\title{
Forensic-Pathological Analysis of Blunt Cardiac Rupture Involving the Relationship between Injury and Disease: 2 Cases Report and Review of the Literature
}

\author{
Qi Wang1, Lingyun Yang2, Yinming Zhang1, Yao Yao', Haijun He1, Zhenyuan Wang1* \\ ${ }^{1}$ School of Forensic Science and Medicine, Xi'an Jiaotong University, Xi'an, China \\ ${ }^{2}$ Sanyuan Branch of Xianyang Public Security, Sanyuan, China \\ Email: "wzy218@mail.xjtu.edu.cn
}

Received 29 January 2016; accepted 26 March 2016; published 31 March 2016

Copyright (C) 2016 by authors and Scientific Research Publishing Inc.

This work is licensed under the Creative Commons Attribution International License (CC BY). http://creativecommons.org/licenses/by/4.0/

\section{(c) (i) Open Access}

\begin{abstract}
Blunt cardiac rupture is a characteristic of high death rates and rapid death process. But sometimes it is hard to find out the cause of cardiac rupture of traumatized patients, especially when it relates the relationship between injury and disease. In the 2 cases reported herein, both of the 2 patients had pre-existent cardiac pathological changes when suffered from traumatic injury. Our aim is to evaluate autopsy findings from a medicolegal point of view, and offer our proposals on how to deal with this sort of cases.
\end{abstract}

Keywords

Heart, Rupture, Cause, Forensic Pathology

\section{Introduction}

Blunt cardiac rupture (BCR), being a characteristic of high death rates and rapid death process, is found mostly in falling injury and traffic accident [1] [2]. The most common manifestations of BCR are cardiac tamponade and exsanguinating haemorrhage with massive haemothorax which are both very dangerous to patients [3]. From 2000 to 2005, according to the data of the American College of Surgeons National Trauma Databank (NTDB), the incidence of cardiac rupture was only $0.045 \%$. Nevertheless, the on-scene mortality was $78 \%$ to $87 \%$, the overall mortality was $89.2 \%$ [4] [5]. There are high risk factors of cardiac rupture, including blunt

${ }^{*}$ Corresponding author.

How to cite this paper: Wang, W., Yang, L.Y., Zhang, Y.M., Yao, Y., He, H.J. and Wang, Z.Y. (2016) Forensic-Pathological Analysis of Blunt Cardiac Rupture Involving the Relationship between Injury and Disease: 2 Cases Report and Review of the Literature. Forensic Medicine and Anatomy Research, 4, 23-28. http://dx.doi.org/10.4236/fmar.2016.42004 
trauma, myocardial infarction, subepicardial aneurysm, pseudoaneurysm, etc. In some extreme cases, cardiac rupture may result from a complex interplay between injury and disease. Thus, for forensic pathologists, the confirmation of cardiac rupture is a key point in analyzing the nature of such cases, and clearing the relationship between the injury and disease. However, there is no comprehensive guideline to this medicolegal dilemma. So, we describe here 2 cases with CR caused by injury and disease, and offer our proposals on how to deal with this sort of cases in the discussion part.

\section{Case 1}

A 37-year-old man, while riding an electric mobile, collided with a bicycle from the opposite way and sustained multiple injuries. He was declared dead after rescue measures proved ineffectual. Forensic autopsy was performed the next day. On inspection, chest and abdomen were unremarkable, and several soft tissue injuries were found on other apartments of the body. Internal examination revealed no pathological lesions such as fractures and hemorrhage were detected on the chest wall or in the rib cage musculature. There was a rupture of soft tissue with slight hematocele around the spleen in the abdominal cavity. Pericardium was intact, with hematocele and clotted blood having a volume of $500 \mathrm{ml}$ in the pericardial cavity. An irregular rupture measuring $0.5 \mathrm{~cm} \times$ ventricular cavity deep was present on the right ventricle with multiple hemorrhagic regions surrounding. Multiple areas of bilateral cardiac muscle, especially the right side, were substituted by transmural fibrofatty tissue. The histopathologic result of the rupture showed the right ventricular wall was thinned severely owing to myocyte replacement by transmural fibrofatty infiltration and lesser amounts of fibrosis (Figure 1).

\section{Case 2}

A 37-year-old man, with a history of drug abuse, died very quickly after fighting with others. The medicolegal autopsy showed there were 2 irregular contusions on the left chest, multiple contusions with overlying abrasions on the left chest wall, and 2 contusions on other apartments. Regions beside the midclavicular line showed the fracture of the left 6th rib, as well as surrounding muscular hemorrhage. The heart weighed $301 \mathrm{~g}$, and on the left ventricular apex a full-thickness rupture of $0.7 \mathrm{~cm}$ with a hemorrhagic region surrounding was detected (Figure 2). The left anterior descending coronary artery is narrowed by 60\%. The histopathologic examination showed adipose tissues of epicardium increased significantly, and the structure of myocardial interstitium turned loose. Nonetheless, there is no evidence of myocardial necrosis. Toxicological analysis showed methamphetamine was detected from both the blood and hair of the patient.

\section{Discussion}

Firstly, cardiac rupture's epidemiological characteristics must be taken into consideration. Cardiac rupture is the most severe form of blunt chest injury [6]-[8]. Several mechanisms for blunt cardiac rupture have been theorized: 1) direct transmission of force to the heart, 2) compression between the sternum and vertebral column, 3) concussion, 4) penetration from broken ribs or sternal fragments, 5) blast injury, 6) acceleration or deceleration of

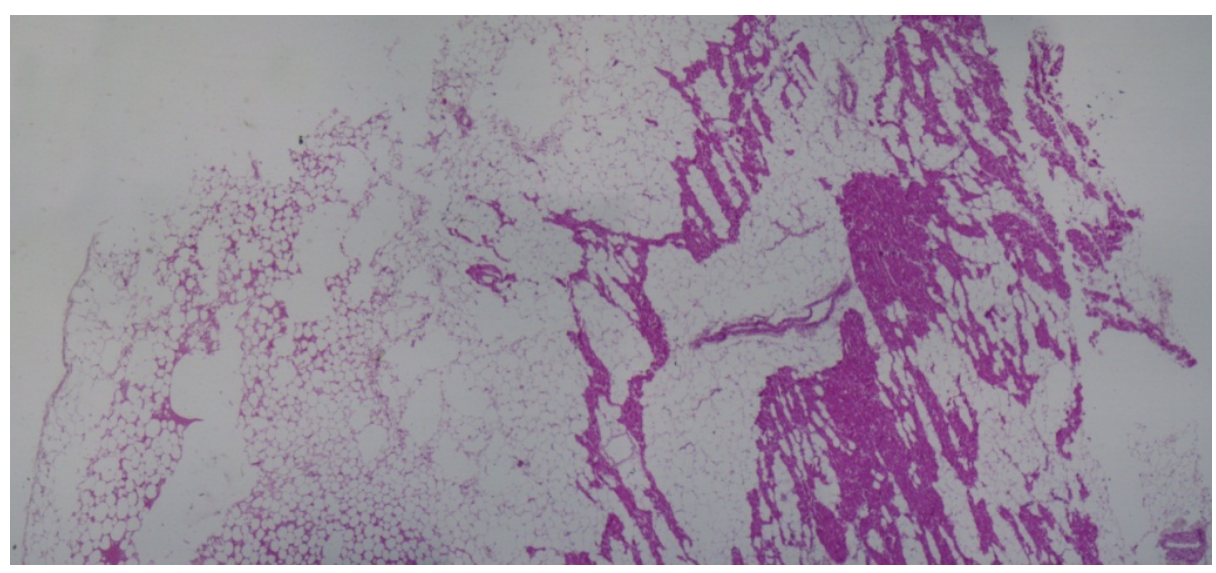

Figure 1. The transmural fibrofatty replacement of the right ventricle free wall $(H \& E, 10 \times)$. 


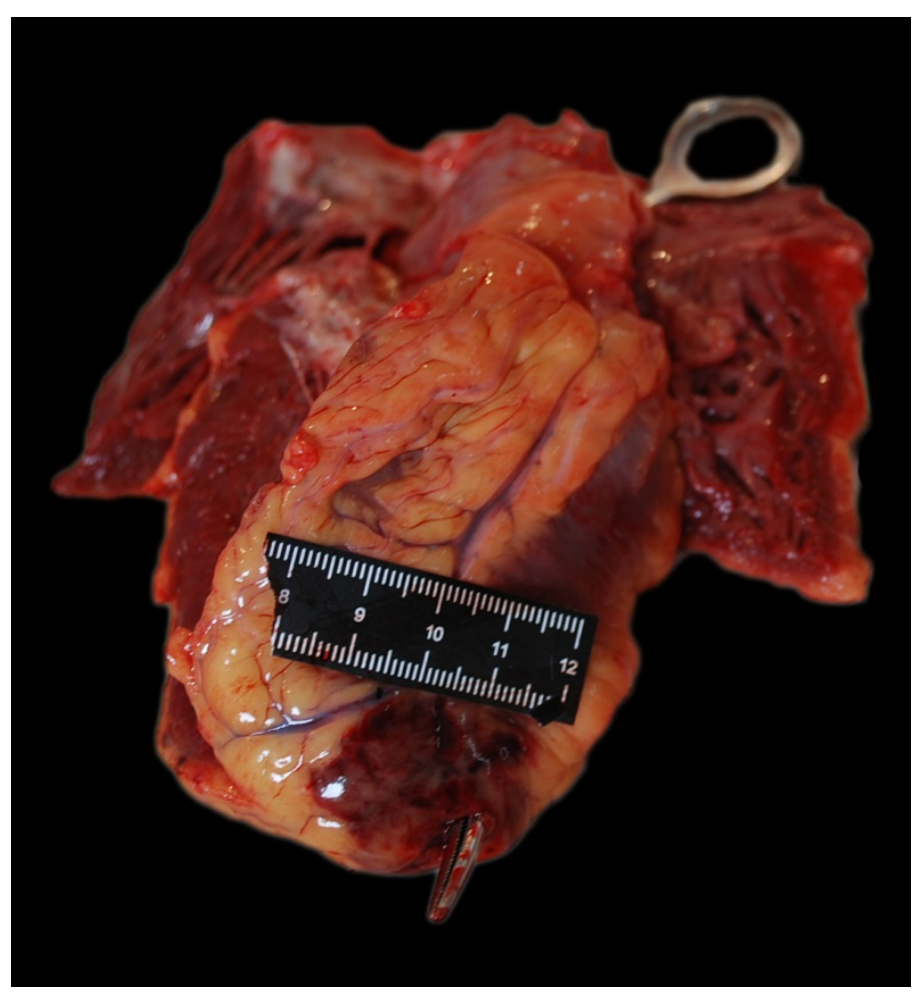

Figure 2. The full-thickness rupture on the left ventricular apex with a hemorrhagic region surrounding.

the heart and great vessels, and 7) the "hydraulic ram" effect in which sudden compression of abdominal and/or extremity veins forcibly distends the cardiac chambers [6] [7] [9]. Sometimes more than one mechanism may be involved in one case. Ruptures can be sporadic or multiple and occur in atriums, ventricles, interatrial septum, interventricular septum, heart valves, blood vessels and papillary muscles. Totally, the left and right ventricles are reported with equal frequency, followed by the right atrium and the left atrium [10]. When the precordial region suffers from traumatic injury, the closer the region exists to the apex, the greater the probability of its rupture, the apex or ventricle ruptures are mostly caused by direct precordial impact, the atrium or the cardio great vessels ruptures is caused mostly by violent deceleration forces [10]. Besides, intracardiac structures, such as ventricular septum, valves, chordae tendineaes and papillary muscles, are not the parts where external forces effect on directly, so they always rupture alone with the cardiac rupture of the free wall unless those structures have pre-existent pathological changes. Under the circumstances, observation the macroscopic and microscopic changes on the margins of rupture wound will be helpful to define if there is a risk factor for cardiac rupture.

Then, it is reasonable to observe microscopic morphological changes, so as to determine if there are any abnormalities in the heart. The complexity of cardiac structure and the variety of external forces make it hard to explain the various mechanisms of cardiac rupture, and especially when different mechanisms interact in a complex manner to produce the broad spectrum of blunt cardiac injuries. Meanwhile, it has been proved that a diseased heart is more susceptible to traumatic injury than a normal one. The diseased heart is more likely to rupture at the weak point of fragile myocardium like the areas of recent myocardial infarction [11], myocardial contusion [12], anterior operative scar [13] and extensive fatty infiltration [14]. Therefore, even minor impact may be the triggering mechanism leading to cardiac rupture, and the lesion on the body surface may be none or few.

It is also quick essential to deduce the way of the external force by grasping the information about the scenes and cases sufficiently. And other injuries associated with heart rupture, just like rib fractures, brain injury, contusions and etc, is also conducive to judge the magnitude level, the direction and the characteristic of the force applied on the body. Besides, judge if the external force can cause the rupture alone, or say if the locations, sizes and depths of the cardiac rupture conform to the external force or not. If not, forensic pathologists should define whether or not the dead have had old myocardial infarction (OMI), cardiomyopathy, fatty heart, cardiac valvular 
disease, or other pre-existent pathological changes heart diseases, and investigate the severity of them by a comprehensive anatomy and microscopic examination. But it is not to say the degree of injury determine its participation of death. It is noted that cardiac rupture may be produced by the compression of the chest or/and by the increased intrathoracic pressure transmitted from a stroke to the chest, even without visible marks of external injury [15] [16]. Sometimes, the injury doesn't lead to death and only overlap the time of cardiac rupture, even if the sudden death occurs after suffering from blunt trauma [17].

Furthermore, cardiac rupture can also be a rare iatrogenic complication during cardio-pulmonary resuscitation (CPR) [18] [19]. Any cardiac injury caused by iatrogenic factors, such as ruptures pierced by fractured ribs during CPR, should be excluded.It is easy to be overlooked. In some reports [11] [16], the authors did not exclude the influence of CPR or other iatrogenic factors during the process of cardiac rupture. Forensic pathologists should be aware of the characteristic of CPR-related cardiac rupture as follows. Right ventricular ruptures may be related to chest compression [20] [21]. However, left ventricular ruptures are unrelated to cardiac massage [22], but can be perforated by the tip of a fractured rib resulting from CPR [23].

For those basic points, we present our analysis of the 2 cases. In Case 1, the micromorphologic changes of transmural fibrofatty replacement of the right ventricular free wall and the minimal or absent of the violence on the patient's chest (no obvious signs of chest trauma) suggested arrhythmogenic right ventricular cardiomyopathy (ARVC) [24] [25] is considerable. ARVC is an inherited disease of the myocardium, and is characterized by fibrofatty replacement leading to ventricular arrhythmias and sudden death in young people and athletes [26]. In case 2, with drug addicting, the patient's cardiac muscle already showed atrophic change with less compliance than normal one. Moreover, severe atherosclerosis was observed in a branch of his coronary artery, which was enough to make the victim die from myocardial ischemia. Plenty of evidence reviews that methamphetamine abuse is likely to induce vasospasm, decrease cardiac oxygen supply, lead to myocardial ischemia and exacerbate the risk of cardiac pathology from other causes [27] [28]. However, we didn't find myocardial necrosis in the patient's heart, which illustrated that the exposure to methamphetamine and the pathological changes in coronary artery did nothing significant to the cardiac rupture.

\section{Conclusion}

In case 1, we concluded that the patient was dead from cardiac tamponade by the cardiomyopathy of the right ventricle combining with right ventricular rupture, and the force was an assistant factor. In case 2, the death was mainly caused by the external force, which led to cardiac rupture and cardiac tamponade, with drug abuse and the cardiac pathological changes being considered as an assistant factor.

\section{Acknowledgements}

The work was partly supported by the Council of National Natural Science Foundation of China (81471819).

\section{References}

[1] Maron, B.J. and Estes III, N.A. (2010) Commotio Cordis. The New England Journal of Medicine, 362, 917-927. http://dx.doi.org/10.1056/NEJMra0910111

[2] Teixeira, P.G., Georgiou, C., Inaba, K., Dubose, J., Plurad, D., Chan, L.S., Toms, C., Noguchi, T.T. and Demetriades, D. (2009) Blunt Cardiac Trauma: Lessons Learned from the Medical Examiner. The Journal of Trauma, 67, 1259-1264. http://dx.doi.org/10.1097/TA.0b013e318187a2d2

[3] Nan, Y.Y., Lu, M.S., Liu, K.S., Huang, Y.K., Tsai, F.C., Chu, J.J. and Lin, P.J. (2009) Blunt Traumatic Cardiac Rupture: Therapeutic Options and Outcomes. Injury, 40, 938-945. http://dx.doi.org/10.1016/j.injury.2009.05.016

[4] Teixeira, P.G., Inaba, K., Oncel, D., DuBose, J., Chan, L., Rhee, P., Salim, A., Browder, T., Brown, C. and Demetriades, D. (2009) Blunt Cardiac Rupture: A 5-Year NTDB Analysis. The Journal of Trauma, 67, 788-791. http://dx.doi.org/10.1097/TA.0b013e3181825bd8

[5] Turan, A.A., Karayel, F.A., Akyildiz, E., Pakis, I., Uzun, I., Gurpinar, K., Atilmis, U. and Kir, Z. (2010) Cardiac Injuries Caused by Blunt Trauma: An Autopsy Based Assessment of the Injury Pattern. Journal of Forensic Sciences, 55, 82-84. http://dx.doi.org/10.1111/j.1556-4029.2009.01207.x

[6] Bintz, M., Gall, W.E. and Harbin, D. (1992) Blunt Myocardial Disruption: Report of an Unusual Case and Literature review. The Journal of Trauma, 33, 933-934. http://dx.doi.org/10.1097/00005373-199212000-00028 
[7] Parmley, L.F., Manion, W.C. and Mattingly, T.W. (1958) Nonpenetrating Traumatic Injury of the Heart. Circulation, 18, 371-396. http://dx.doi.org/10.1161/01.CIR.18.3.371

[8] Brathwaite, C.E.M., Rodriguez, A., Turney, S.Z., Dunham, C.M. and Cowley, R.A. (1990) Blunt Traumatic Cardiac Rupture-A 5-Year Experience. Annals of Surgery, 212, 701-704. http://dx.doi.org/10.1097/00000658-199012000-00008

[9] Bright, E.F. and Beck, C.S. (1935) Nonpenetrating Wounds of the Heart-A Clinical and Experimental Study. American Heart Journal, 10, 293-321. http://dx.doi.org/10.1016/S0002-8703(35)90312-X

[10] Grande, A.M., Rinaldi, M., Pasquino, S., Dore, R. and Vigano, M. (2003) Nonpenetrating Right Atrial and Pericardial Trauma. The Annals of Thoracic Surgery, 76, 923-925. http://dx.doi.org/10.1016/S0003-4975(03)00197-8

[11] Lin, C.H., Chen, S.Y., Chang, W.T., Chen, S.C. and Chen, W.J. (2005) Cardiac Rupture after Minor Blunt Chest Injury as a Result of Occult Recent Myocardial Infarction. Resuscitation, 67, 149-150. http://dx.doi.org/10.1016/j.resuscitation.2005.04.011

[12] Lassus, J., Tulikoura, I., Konttinen, Y.T. and Santavirta, S. (2001) Myocardial Contusion as, a Cause of Delayed Cardiac Rupture. A Case Report. Injury, 32, 789-793. http://dx.doi.org/10.1016/S0020-1383(01)00105-X

[13] Utter, G.H., Scherer, L.A. and Wisner, D.H. (2004) Blunt Cardiac Rupture in a Patient with Prior Ventricular Septal Defect Repair: A Case Report. The Journal of Trauma, 57, 635-637. http://dx.doi.org/10.1097/01.TA.0000135351.39516.D6

[14] Godinez-Valdez, V.H., Cazares-Campos, I., Aranda-Fraustro, A., Lopez-Jimenez, F., Cardenas, M. and Marquez, M.F. (2012) Cardiac Rupture in a Patient with an Acute Myocardial Infarction and Extensive Fatty Infiltration of the Heart (“Adipositas Cordis”). International Journal of Cardiology, 154, e62-e64. http://dx.doi.org/10.1016/j.ijcard.2011.06.060

[15] Birincioglu, I., Turan, N. and Can, M. (2011) Rupture of Heart with all Layers after a Massive Blunt Thoracic Trauma without Any Lesion on the Bones: A Case Report. Turkish Journal of Trauma \& Emergency Surgery, 17, 87-89. http://dx.doi.org/10.5505/tjtes.2011.79027

[16] Turkmen, N., Bilgen, M.S., Eren, B., Fedakar, R. and Senel, B. (2009) Cardiac Rupture Due to Fall: A Case Study. Ann Acad Med Singap, 38, 156-157.

[17] Udhayabanu, R., Parmar, P. and Balaraman, R. (2012) Sudden Death Due to Cardiac Rupture-A Case Report. International Journal of Medical and Pharmaceutical Sciences, 3, 11-15.

[18] Machii, M., Inaba, H., Nakae, H., Suzuki, I. and Tanaka, H. (2000) Cardiac Rupture by Penetration of Fractured Sternum: A Rare Complication of Cardiopulmonary Resuscitation. Resuscitation, 43, 151-153. http://dx.doi.org/10.1016/S0300-9572(99)00137-9

[19] Tattoli, L., Maselli, E., Romanelli, M.C., Di Vella, G. and Solarino, B. (2014) Complete Cardiac Rupture Associated with Closed Chest Cardiac Massage: Case Report and Review of the Literature. Journal of Forensic Sciences, 59, 564-567. http://dx.doi.org/10.1111/1556-4029.12340

[20] Klintschar, M., Darok, M. and Radner, H. (1998) Massive Injury to the Heart after Attempted Active CompressionDecompression Cardiopulmonary Resuscitation. International Journal of Legal Medicine, 111, 93-96. http://dx.doi.org/10.1007/s004140050123

[21] Sokolove, P.E., Willis-Shore, J. and Panacek, E.A. (2002) Exsanguination Due to Right Ventricular Rupture during Closed-Chest Cardiopulmonary Resuscitation. Journal of Emergency Medicine, 23, 161-164. http://dx.doi.org/10.1016/S0736-4679(02)00504-8

[22] Takada, A., Saito, K. and Kobayashi, M. (2003) Cardiopulmonary Resuscitation Does Not Cause Left Ventricular Rupture of the Heart with Acute Myocardial Infarction: A Pathological Analysis of 77 Autopsy Cases. Legal Medicine, 5, 27-33. http://dx.doi.org/10.1016/S1344-6223(03)00002-6

[23] Noffsinger, A.E., Blisard, K.S. and Balko, M.G. (1991) Cardiac Laceration and Pericardial Tamponade Due to Cardiopulmonary-Resuscitation after Myocardial-Infarction. Journal of Forensic Sciences, 36, 1760-1764. http://dx.doi.org/10.1520/JFS13201J

[24] Basso, C., Corrado, D., Marcus, F.I., Nava, A. and Thiene, G. (2009) Arrhythmogenic Right Ventricular Cardiomyopathy. Lancet, 373, 1289-1300. http://dx.doi.org/10.1016/S0140-6736(09)60256-7

[25] Ellinor, P.T., MacRae, C.A. and Thierfelder, L. (2010) Arrhythmogenic Right Ventricular Cardiomyopathy. Heart Failure Clinics, 6, 161-77. http://dx.doi.org/10.1016/j.hfc.2009.12.003

[26] Marra, M.P., Rizzo, S., Bauce, B., De Lazzari, M., Pilichou, K., Corrado, D., Thiene, G., Iliceto, S. and Basso, C. (2015) Arrhythmogenic Right Ventricular Cardiomyopathy Contribution of Cardiac Magnetic Resonance Imaging to the Diagnosis. Herz, 40, 600-606. http://dx.doi.org/10.1007/s00059-015-4228-0 
[27] Kaye, S., McKetin, R., Duflou, J. and Darke, S. (2007) Methamphetamine and Cardiovascular Pathology: A Review of the Evidence. Addiction, 102, 1204-1211. http://dx.doi.org/10.1111/j.1360-0443.2007.01874.X

[28] Hawley, L.A., Auten, J.D., Matteucci, M.J., Decker, L., Hurst, N., Beer, W. and Clark, R.F. (2013) Cardiac Complications of Adult Methamphetamine Exposures. The Journal of Emergency Medicine, 45, 821-827.

http://dx.doi.org/10.1016/j.jemermed.2013.04.061 